\title{
MJERENJE KVALITETE ŽIVOTA VEZANE UZ ZDRAVLJE KAO MJERILO USPJEŠNOSTI ZDRAVSTVENE SKRBI
}

\author{
Boris Kovač \\ Fakultet zdravstvenih studija Sveučilišta u Mostaru, Bosna i Hercegovina \\ Rad je primljen 7.4.2017. Rad je recenziran 15.4.2017. Rad je prihvaćen 20.4.2017.
}

\section{SAŽETAK}

U medicinskoj znanosti mjerenje kvalitete života i kvalitete života vezane uz zdravlje predstavljaju prihvaćene instrumente za procjenu utjecaja bolesti i različitih postupaka liječenja na bolesnikovo tjelesno ili emocionalno stanje u svakodnevnim aktivnostima. Kvaliteta života vezana uz zdravlje predstavlja dio općeg koncepta kvalitete života koji se odnosi specifično na zdravlje osobe, a označava mjerenje funkcioniranja, blagostanja i opće percepcije zdravlja bolesnika u tri domene: fizičkoj, mentalnoj i socijalnoj. Instrumenti za mjerenje kvalitete života vezana uz zdravlje temelje se na konceptu zdravlja koji je višedimenzionalan, a izvor informacija je sam bolesnik. Mogu se klasificirati kao generički ili specifični. Generički instrumenti procjenjuju koncept zdravlja koji predstavlja temeljnu humanu vrijednost i odnose se na zdravstveno stanje i blagostanje svakog pojedinca, neovisno o dobi, bolesti ili načinu liječenja. Specifični instrumenti usmjereni su na specifičnu bolest, stanje ili liječenje. Danas u suvremenoj kliničkoj medicini postoje sve veći zahtjevi za ispitivanjem učinkovitosti, neškodljivosti i isplativosti novih strategija liječenja koje, osim omjera troškova i koristi, uključuju i bolesnikov osjećaj zdravlja kao mjerilo uspješnosti liječenja.

Cilj ovoga rada prikazati je temeljnu metodologiju, načine i značaj mjerenja kvalitete života vezane uz zdravlje u procesu evaluacije uspješnosti zdravstvene skrbi.

Ključne riječi: kvaliteta života, zdravlje, bolest, upitnik.

Osoba za razmjenu informacija:

Boris Kovač

E mail: boris.v.kovac@gmail.com

\section{UVOD}

Pristupi u proučavanju kvalitete života mijenjali su se kroz vrijeme, a njene su definicije heterogene prirode. Kvaliteta života je multidimenzionalni pojam te je predmet interesa mnogih disciplina, kao što su medicina, javno zdravstvo, pravo, filozofija, psihologija, ekonomija i sociologija. Postoje brojne objavljene mjere kvalitete života, međutim među znanstvenicima još uvijek nedostaje konsenzus o definiciji, što se odražava u postojanju velikog broja instrumenata koji se koriste za procjenu kvalitete života (1).

Od vremena kada je Svjetska zdravstvena organizacija (SZO) definirala pojam zdravlja počinje rasti interes i za kvalitetu života. Danas kvaliteta života ima značajno mjesto u praksi zdravstvene zaštite,

ali i u znanstveno istraživačkom radu. Za mnoge kliničare kvaliteta života vezana uz zdravlje (KŽVZ) novi je termin, ali svakako ne i novi koncept. Povezivanje pojma zdravlja s kvalitetom života vrijedna je novost u medicini. Tako je i kao dostatan pokazatelj zdravlja odbačen broj godina koje čovjek proživi, jer ne pokazuje i kvalitetu čovjekova života. Pojam se kvalitete života u medicini može odrediti i kao mogućnost da nakon poduzetog liječenja bolesnik živi tjelesno, duševno i socijalno što sličnije životu prije liječenja. U proteklih dvadesetak godina jedno od najznačajnijih napredaka u području zdravstvenog sustava bilo je prepoznavanje središnje uloge bolesnika i njegovog doživljavanja zdravlja u praćenju kvalitete i ishoda liječenja (2). Ishod liječenja koji 
je do tada uvijek procjenjivan kao preživljavanje, $\mathrm{u}$ novije vrijeme označava u kojoj se mjeri promjene bolesnikova funkcioniranja ili dobrog osjećanja podudaraju s njegovim potrebama i očekivanjima. U medicinskoj znanosti mjerenje zdravlja, praćenje kvalitete života i kvalitete života vezane uz zdravlje jednako su prihvaćeni instrumenti za procjenu utjecaja bolesti, različitih postupaka liječenja ili kompleksnih terapijskih zahvata na bolesnikovo tjelesno i emocionalno stanje u svakodnevnim aktivnostima (3).

\section{POJMOVNI OKVIRI KVALITETE ŽIVOTA}

U posljednja tri desetljeća kvaliteta života postala je važan predmet istraživanja u različitim disciplinama. Danas je procjena kvalitete života sastavni dio evaluacije rehabilitacijskih i terapijskih postupaka. Pitanje čimbenika osobne kvalitete života vrlo je aktualno kako na području zdravstvene zaštite kroničnih bolesnika, tako i opće populacije. Iako se koncept kvalitete života učestalo koristi, teško ga je definirati. Definicije kvalitete života razlikuju se, kao i načini kojima se ona procjenjuje. Raphael i suradnici navode kako i metoda procjene može utjecati na definiranje kvalitete života (4).

Tako, na primjer, medicinski pristup će naglašavati utjecaj bolesti i teškoća na kvalitetu života, dok će se pristup usmjeren na zdravlje fokusirati na zdravlje i sposobnosti koje su nužne u svakodnevnom životu. Istraživači se, međutim, slažu da je koncept kvalitete života multidimenzionalan i subjektivan $(5,6)$. Jedna od definicija kvalitetu života opisuje kao sveukupno blagostanje na koje utječu objektivni pokazatelji, a veliki udio ima i subjektivna percepcija, te vrednovanje tjelesnog, emocionalnog, socijalnog i materijalnog blagostanja, osobnog razvoja i svrhovite aktivnosti. Sve spomenuto pod utjecajem je osobnih vrijednosti pojedinca (7).

Kvaliteta života je multidimenzionalna. Ona ovisi o općem zdravlju, psihološkom statusu, stupnju neovisnosti u obavljanju svakodnevnih aktivnosti, socijalnim odnosima, okruženju i mogućnosti realizacije osobnih ciljeva. Zdravstveni status je samo djelić onog što ulazi u kategoriju kvalitete življenja, opisujući samo tjelesni i psihološki (emocionalni) aspekt. Skupina za kvalitetu života Svjetske zdravstvene organizacije definira kvalitetu života u kontekstu kulture u kojoj osoba živi i u povezanosti s osobnim ciljevima, očekivanjima i brigama. Kvalitetu života promatraju pod utjecajem tjelesnog zdravlja, psihološkog stanja, stupnja samostalnosti, povezanosti s drugim ljudima, kao i okolinom (8).

Za razumijevanje zadovoljstva životom neke osobe potreban je uvid u strukturu zadovoljstva i strukturu faktora koji određuju osobnu kvalitetu života, te koliko pojedini faktori doprinose ukupnoj kvaliteti. Danas je jasno da je kvaliteta života sveukupno blagostanje na koje utječu objektivni pokazatelji, a veliki udio ima i subjektivna percepcija te vrednovanje tjelesnog, materijalnog, socijalnog i emotivnog blagostanja, osobni razvoj i svrhovita aktivnost. Sve spomenuto pod utjecajem je osobnih vrijednosti pojedinca (9).

\section{KVALITETA ŽIVOTA VEZANA UZ ZDRAVLJE}

Bolest je nedvojbeno jedan od vanjskih čimbenika koji negativno utječe na život pojedinca. Može se reći da je utjecaj bolesti na kvalitetu života višestruk. Bolest ne samo da utječe u smislu fizičkih simptoma i time limitira funkcioniranje, nego su tu prisutni i posredni učinci, kao što su to promjene u radnoj sposobnosti, potencijalna izolacija, loše navike i sl. Razmatranja o kvaliteti života pacijenta duboko su utkana u sva područja zdravstvene skrbi, a posebice u područje zdravstvene njege. U osnovi zdravstvene njege nalazi se usmjerenost na zadovoljavanju osnovnih ljudskih potreba. Brojni teoretičari zagovaraju holistički pristup pri rješavanju pacijentovih problema i poteškoća vezanih upravo uz ljudske potrebe poticanje samozbrinjavanja i uspostavljanje najvećeg stupnja samostalnosti pacijenta, a time i najviše razine kvalitete života pacijenta (10).

Koncem dvadesetog stoljeća dolazi do značajnog napretka u stvaranju koncepta zdravlja prema mnogo široj koncepciji KŽVZ, a s tim u svezi i napretka u razvijanju metoda za mjerenje zdravlja uz pomoć standardiziranih upitnika koji ispituju zdravlje ispitanika, ali i njegovog osobni stav prema zdravlju, 
njegovim tegobama, bolestima i pruženoj zdravstvenoj zaštiti. KVZŽ se odnosi na stupanj u kojem tjelesna disfunkcija, bol i neugoda ograničavaju svakodnevno ponašanje ljudi, njihove socijalne aktivnosti, psihičku dobrobit i druge vidove opće kvalitete življenja, prema prosudbi same osobe Subjektivno je zdravlje ili samoprocjena zdravlja za većinu osoba prvenstvena odrednica kvalitete življenja povezane sa zdravljem (11).

KVZŽ je mnogo specifičniji termin od kvaliteta života i pogodniji je za uporabu jer odražava pacijentovu procjenu i zadovoljstvo trenutnim stupnjem funkcioniranja $\mathrm{u}$ usporedbi s onim što on smatra mogućim ili idealnim (12). Subjektivno zdravlje ili samoprocjena zdravlja pod utjecajem je bioloških i brojnih nebioloških čimbenika: ličnosti, motivacije, socioekonomskoga statusa, dostupnosti zdravstvene skrbi,mreže socijalne podrške, osobnih i kulturnih vjerovanja te zdravstvenoga ponašanja. Samoprocjena zdravlja, kao subjektivna mjera, povezana je s dobrobiti osobe jer obuhvaća procjenu i tjelesnoga i emocionalnoga zdravlja. Utvrđeno je da je subjektivno zdravlje, za većinu osoba, prvenstvena odrednica KVZŽ. Stoga je često uključena među pokazatelje kvalitete življenja povezane sa zdravljem, kao i funkcionalna sposobnost (13).

\section{ZAŠTO MJERITI KVALITETU ŽIVOTA VEZANU UZ ZDRAVLJE?}

Ishod liječenja ili medicinskog tretmana mjeri se još uvijek godinama preživljenja ili ulaskom laboratorijskih vrijednosti u okvire "normalne raspodjele”. Ipak, terapijski se učinci danas više ne mogu uspoređivati samo na temelju tih parametara već $\mathrm{i}$ poboljšanja kvalitete života. Interes seže mnogo dalje od objektivnih pokazatelja uspješnosti liječenja (npr. laboratorijski rezultati, krvni tlak, itd.), jer biokemijski parametri mogu indicirati potrebu za promjenom ili redukcijom terapije, ali ne moraju uvijek korelirati sa subjektivnim osjećajem pacijenta. Liječenje može pokazati znatno poboljšanje laboratorijskih parametara, ali se bolesnik ne mora nužno osjećati bolje. Trajanje života može biti produljeno, dok bol i patnja ostaju nedefinirani (14).
Na primjer, dijabetički bolesnik ne može smatrati svoj život kvalitetnim ako je glikemija uredna, a pati od posljedica nefro ili neuropatije, kao što ni onkološki bolesnik nakon radikalnog zahvata ne smatra svoj život kvalitetnim ako preživi i više godina, ali vezan uz krevet. S druge strane, mišljenje da svaka osoba koja trpi od značajnih zdravstvenih ili funkcijskih smetnji ima lošu kvalitetu življenja nije točna. Čak i osobe s izraženim hendikepom mogu navesti dobru kvalitetu življenja unatoč teškoćama u zadovoljavanju dnevnih potreba, ako je njihov socijalni život zadovoljavajući. Ponekad studija kvalitete života može otkriti prethodno nepoznate činjenice o nekoj bolesti ili stanju (15). Primjerice, istraživanje kvalitete života u okviru hipertireoidizma otkrilo je znatne poremećaje sna i kvalitete odmora. Ti se poremećaji mogu lako ukloniti, ali dosad takva povezanost nije bila poznata niti opisana u medicinskim udžbenicima (16).

Zato je osamdesetih godina dvadesetog stoljeća naglo porastao interes za procjenu kvalitete života. Mjerenje terapijskih učinaka kao dokaz poboljšanja kvalitete zdravstvene zaštite postaje bitan činitelj određivanja zdravstvene politike. Oni koji zdravstvo financiraju očekuju mjerljive pokazatelje za svoja ulaganja, a konzumenti traže informaciju o uspješnosti liječenja objektivnom procjenom subjektivnog. Naime,mjerenjem kvalitete života moguće je procijeniti efekte liječenja u kliničkim istraživanjima, odnosno usporediti efekte medicinskog postupka u različitim stanjima ili bolestima (17).

\section{METODE PROCJENE KVALITETE ŽIVOTA VEZANE UZ ZDRAVLJE}

Tijekom proteklih desetljeća dogodilo se mnogo značajnih promjena u metodici otkrivanja kvalitete života. Najvažniji je zasigurno prijelaz od procjene temeljene na dojmovima liječnika k osobnoj, pacijentovoj prosudbi stanja, koji najbolje može izraziti svoju percepciju zdravlja ili bolesti. Vremenom su istraživanja postala multidimenzionalnija, a posebna se pozornost usmjerava standardizaciji upitnika i multilingvalnoj prilagodbi. Kompleksnost otkrivanja kakvoće života očituje se i u mogućem podcjenjivanju funkcionalnog statusa ili nekih fizikalnih 
simptoma (npr. bol, dispneja) prema prosudbi ispitivača, ili pak precjenjivanju psihološki inducirane nelagode (tjeskoba, depresija, distres). Logična posljedica loše prosudbe je neprimjereno liječenje. Velik broj raznih metoda kojima se pokušava otkriti stupanj kvalitete života te ocijeniti zdravstveni potencijal, indirektni je pokazatelj neujednačenosti pristupa, odnosno potrebe za standardizacijom (18).

Mjerenje kvalitete života može biti generičko ili specifično (s obzirom na bolest). Generička studija procjenjuje bolesnikovo cjelokupno tjelesno i mentalno zdravlje istražujući različite tipove ili stupnjeve bolesti, različite oblike liječenja ili zdravstvenih intervencija u okviru demografskih ili kulturoloških podskupina. Mjerenjima se zbrajaju različiti koncepti zdravlja ili kvalitete života s obzirom na utjecaj okoline, bolesti ili populacijskih zbivanja (19).

Mjerenja kvalitete života koja su specifična za neku bolest obrađuju pacijente s istom dijagnozom i vezana su uz one aspekte bolesti koji su relevantni po mišljenju pacijenta i kliničara. Primjerice, upitnik koji je specifičan analizira jačinu stiska šake u artritičara, spirometrijske pokazatelje tijekom tjelesne aktivnosti u bolesnika s kroničnom bolesti pluća, broj i trajanje valova vrućine. Uobičajen je pristup kombinacija generičkog i upitnika specifičnog za neku bolest. Često se istraživanja kvalitete života upotpunjuju kliničkim podatcima (20).

Konačno, kad su podatci iz upitnika prikupljeni i obrađeni, potrebno je nalaze interpretirati. U okviru ovog razmjerno novog znanstvenog područja to nije jednostavno. Na žalost, nema dovoljno temeljnih istraživanja koja bi odredila klinički znakovitu razliku kvalitete življenja prije i nakon liječenja, odnosno medicinskog postupka. Svaki istraživač mora pokušati dizajnirati studiju tako da može otkriti minimalnu, klinički znakovitu razliku. Ona predstavlja najmanju razliku kvalitete života koja pokazuje potrebu za promjenom terapijskog pristupa. Razlika indeksa kvalitete života je ili signal za promjenu nabolje, prema kojemu je pacijentu potrebno manje njege, ili pak pokazatelj pogoršanja stanja, kad je potrebna pojačana skrb. Još uvijek postoje stotine bolesti i stanja bez standardiziranog instrumenta za mjerenje KŽVZ. Stoga je pronalaženje novih metoda ili standardizacija starih osnovna zadaća znanstvene discipline koja istražuje kvalitetu življenja (21).

\section{INSTRUMENTI ZA MJERENJE KVALITETE ŽIVOTA VEZANE UZ ZDRAVLJE}

Osnovna karakteristika suvremene procjene KVZŽ zbog njene kompleksnosti ogleda se u holističkoj komponenti sadržanoj kroz multidisciplinarani i multidimenzionalni pristup $s$ višestrukom procjenom svake domene. KVZŽ je teško mjerljiva, a i kada se "izmjeri" teško usporediva kategorija (22). Zbog nemogućnosti izravnog promatranja mnogih dimenzija kvaliteta života, one se evaluiraju teorijom "pitanje - mjerenje". Ova teorija pretpostavlja postojanje stvarne vrijednosti kvalitete koja ne može biti mjerena izravno, ali se može mjeriti neizravno postavljajući niz pitanja koja mjere neke istinite koncepte ili konstrukcije. Na taj se način dobiveni odgovori pretvaraju u numeričke skorove. Dobiveni skorovi se kombiniraju s ljestvicama skorova koje također mogu nastati kombiniranjem. Ako su pitanja pravilno izabrana rezultiraju ljestvicom mjerenja (23).

Instrument za mjerenje KVZŽ je upitnik. Kreiranje izvornog upitnika velik je znanstveni izazov, a proces validacije može trajati godinama. $\mathrm{Na}$ prvi pogled jednostavniji način usvajanja već postojećeg upitnika zapravo je isto toliko težak zadatak. Ako se prevodi s originalnog jezika, potreban je dugotrajan proces uspoređivanja s razumijevanjem, prilagodba lokalnim uvjetima i potrebama uz sudjelovanje međunarodnog koordinacijskog tima.

Dostupni alati mogu se klasificirati kao generički ili specifični (24).

\section{Generički instrumenti}

Generički upitnici za procjenu većeg broja dimenzija kvalitete života imaju najširu primjenu, te se koriste u svrhu određivanja demografskih i međukulturnih razlika u kvaliteti života. Mogu se upotrebljavati kod pojedinih bolesti te u zdravoj populaciji.

Primjer validiranog upitnika ove vrste uključuje Upitnik o kvaliteti života Svjetske zdravstvene organizacije (The World Health Organization Quality of 
Life Questionnaire, WHOQOL-BREF) (25). Upitnik WHOQOL-BREF predstavlja skraćenu verziju upitnika WHOQOL-100 koji je konstruirala SZO u svrhu procjene kvalitete života $(25,26,27)$. Psihometrijska istraživanja su pokazala da je WHOQOL-BREF pouzdan i validan instrument, te visoko korelira s WHOQOL-100, oko 0.89 (25). Zbog manjeg broja pitanja i bržeg rješavanja daje mu se prednost pred WHOQOL-100. Kao rezultat upitnika WHOQOLBREF dobiva se profil kvalitete života koji polazi od modela koji objašnjava kvalitetu života kroz 4 domene: tjelesno zdravlje, psihičko zdravlje, socijalni odnosi i okolina. Bodovna ljestvica usmjerena je pozitivno, što znači da veći broj bodova predstavlja veću kvalitetu života. Upitnik se sastoji od 26 pitanja, a svako se pitanje boduje Likertovom ljestvicom od 1 (najlošije) do 5 (najbolje) (25).

Među najpoznatijim generičkim instrumentima za mjerenje KŽVZ je Upitnik zdravstvenog statusa (engl. Short form health survey - SF-36 (28). Međunarodno je korišten te standardiziran i validiran na brojne jezike uključujući hrvatski. SF-36 se sastoji od 36 pitanja koja se odnose na zdravlje, a izražene su u 8 domena: fizičko funkcioniranje; ograničenja zbog fizičkog zdravlja; tjelesni bolovi; opće zdravlje; vitalnost; socijalno funkcioniranje; ograničenja zbog emocionalnih problema i psihičko zdravlje (29). Koristi se u istraživanjima opće i specifične populacije u svrhu usporedbe relativnog bremena bolesti. Za razliku od WHOQOL-BREF koji mjeri opću kvalitetu života, SF-36 mjeri kvalitetu života vezanu uz zdravlje, koja predstavlja različiti konstrukt, te je stoga prije donošenja odluke o izboru mjernog instrumenta za procjenu kvalitete života, potrebno jasno definirati istraživačko pitanje (30).

Još jedan često upotrebljavan validirani instrument iz ove skupine je EuroQol-5D (EQ-5D). EQ5D definira zdravlje unutar pet dimenzija: pokretljivost, samoskrbljenje, uobičajene aktivnosti, bol ili neugodnost, uznemirenost ili depresija. Svaka od tih dimenzija se dijeli u tri stupnja: nema problema, problem je umjeren, odnosno jak. Što je veći zbroj bodova to je lošija kvaliteta života (31). Proširena verzija ovog upitnika sadrži vizualno analognu ljestvicu (VAS, engl. visual analogue scale) dugačku 20 $\mathrm{cm}$, pri čemu krajnja donja točka označava najgore moguće zdravstveno stanje, a najviša točka najbolje moguće zdravstveno stanje (32). EQ-5D je dostupan na mnogim jezicima.

\section{Specifični instrumenti}

Za bolest specifični instrumentu koriste se za procjenu kvalitete života u osoba s određenim kroničnim bolestima i u osoba sa sličnim simptomima. Usmjereni su na specifične bolesti, dijagnostičke skupine, stanja ili pristupe u liječenju. Rezultati mjerenja mogu se iskazivati kao zasebni rezultati za određenu domenu ili ukupan indeks koji predstavlja zbroj svih ispitivanih zdravstvenih aspekata. Tako se primjerice u pacijenata s reumatoidnim artritisom koristi Skala za mjerenje utjecaja oboljenja od artritisa (engl. Arthritis Impact Measurement Scale) (33), dok se u pacijenata s tumorima upotrebljava Skala Europske organizacije za liječenje oboljelih od raka (engl. European Organization for Research on Treatment of Cancer) (34).

Također mogu se rabiti za evaluaciju terapijskih postupaka. Upitnik PPA (engl. The Prosthetic Profile of the Amputee Person Questionnaire) je upitnik specifičan za osobe s amputacijom. Mjerni je instrument za prikupljane podataka koji se odnose na upotrebu proteze i raznih čimbenika koji mogu utjecati na njezino korištenje u osoba s amputacijom donjih udova (35).

Mjerenje učinka kronične bolesti na kvalitetu života pacijenta bitno je iz razloga što fiziološka mjerenja i laboratorijski parametri ne pružaju dovoljan uvid u pacijentovo psihološko stanje i zadovoljstvo, što je u percepciji samog pacijenta važnije od objektivnih pokazatelja (36). U kliničkoj je praksi često prisutan fenomen da dva pacijenta koja zadovoljavaju iste kliničke kriterije imaju značajno različite rezultate ocjene emocionalnog aspekta kvalitete života ili aktivnosti svakodnevnog života (37). Stoga se instrumenti za procjenu kvalitete života pacijenata sve više upotrebljavaju u praćenju kliničke učinkovitosti zdravstvenih intervencija i planiranja troškova zdravstvenih sustava 


\section{ZAKLJUČAK}

Mjere ishoda liječenja, odnosno rezultata djelovanja zdravstvenog sustava, razvile su se u posljednjih dvadesetak godina od tradicionalnih varijabli kao što su smrtnost, pobol, nastup određenog kliničkog događaja i procjena koštanja liječenja, prema kompleksnim mjerilima usmjerenim na bolesnika. Zanimanje bolesnika, ali i davatelja zdravstvenih usluga, o najboljem, najučinkovitijem liječenju različitih kroničnih bolesti, kao i o vrijednosti zdravstvenog sustava, a ne isključivo o troškovima, usmjerilo je interes prema različitim novim mjerilima u kojima bolesnik sam procjenjuje svoj funkcionalni status i blagostanje, u širokom rasponu od ljestvica funkcionalnih ograničenja do duhovnog aspekta kvalitete života. Mjerenje KŽVZ usmjereno je prema ishodu liječenja, a danas su informacije o funkcioniranju i blagostanju osobe značajne ne samo radi procjene troškova i koristi individualnog liječenja, nego i radi praćenja organizacije i troškova zdravstvenog sustava i njegovog utjecaja na ukupnu populaciju.

\section{LITERATURA}

1. Cummins RA. Objective and Subjective Quality of Life: An Interactive Model. Social Indicators Research. 2000; 52:55-72.

2. Guyatt GH, Feeny DH, Patrick DL. Measuring health-related quality of life. Ann Intern Med. 1993; 118:622-9.

3. Epstein RS, Sherwood LM. From outcomes research to disease management: a guide for the perplexed. Ann Intern Med. 1996; 124:832-9.

4. Raphael D, Brown I, Renwick R, Rootman I. Assessing the quality of life of persons with developmental disabilities: Description of a new model, measuring instruments, and initial findings. International Journal of Disability, Development, and Education. 1996; 43:25-42.

5. Bowling A. The concepts of successful and positive ageing. Family Practice. 1993; 10:449-53.

6. Schumacher M, Olschewski M, and Schulgen G. Assessment ofquality of life in clinical trials. Stat Med, 2001; 10(12):1915-30.

7. Felce D. Perry J. Quality of life: A contribution to its definition and measurement. Cardiff : Mental handicap in Wales applied research unit. 1993; 35:221-36.

8. Skevington SM, Lotfy M, O'Connell KA. The World Health Organization's WHOQOL-BREF quality of life assessment: psychometric properties and results of the international field trial. A report from the WHOQOL group. Qual Life Res. 2004; 13:299-310.

9. Cummins RA. Normative life satisfaction: measurement issues and a homeostatic model. Social Indicators Research. 2003; 64:225-56.

10. Mellor D, Cummins RA, Loquet C. The gold standard for life satisfaction: Confirmation and elaboration using an immaginary scale and qualitative interview. International Journal of Social Research Methodology Theory and Practice. 1999; 2:263-78.

11.Lawton MP. Quality of life and the end of life. U: Birren JE, Schaie KW. (ur.) Handbook of the psychology of aging. San Diego, Academic Press. 2001;593-616.

12. Armstrong D, Caldwell D. Origins of the Concept of Quality of Life in Health Care: a Rhetorical Solution to a Political Problem. Social Theory and Health. 2004; 2(4):361-71.

13. Bosworth HB, Siegler IC, Brummett BH, Barefoot JC, Williams RB, Vitaliano PP, i sur. The relationship between self-rated health and health status among coronary artery patients, Journal of Aging and Health. 1999; 11(4):565-84.

14. Sprangers MA, Aaronson NK. The role health care providers and significant others in evaluating the quality of life of patients with chronic disease: a review. J Clin Epidemiol. 1992; 45:74360.

15. Walker SR, Rosser R. Quality of life assessment and application. MTP Press, Lancaster, N Engl J. Med. 1998; 2(1):46-52.

16. Gerding MN, Terwee CB, Dekker FW, et al. Quality of life in patients with Graves' ophtalmopathy in markedly decreased: measurement by the medical outcomes study instrument. Thyroid. 1997; 7(6):885-9. 
17. Gafni A, Birch S. QALYs and HYEs (healthy years equivalent). Spotting the differences. J Health Econ. 1997; 16(5):601-8.

18. Bowling A. Measuring disease. Buchingham Open University Press. 1995;12(1)34-48.

19. O'Boyle, CA, McGee H, Hickey A, Joyce CRB, Browne J, O'Malley J. The Schedule for the Evaluation of Individual Qual ity of Life. Administration Manual. Department of Psychology. 2002; 22:128-41.

20. Cummins RA. On the trail of the gold standard for life satisfaction. Social Indicators Research. 1995; 35:179-200.

21. Kuehner C, Buerger C. Determinants of subjective quality of life in depressed patients: The role of self-esteem, response styles and social support. Journal of Affective Disorders. 2005; 86:205-13.

22. Garratt A, Schmidt L, Mackintosh A, Fitzpatrick R. Quality of life measurement: bibliographic study of patient assessed health outcome measures. BMJ. 2002; 324:1417-9.

23. Spilker B. Quality of life trials. In: Guide to clinical trials. New York: Raven Press. 1991:370-8.

24. Testa M.A, Simonson D.C, Assessment of Quality of Life Outcomes. N Engl J. Med. 1996; 334(13):835-40.

25. Development of the World Health Organization WHOQOL-BREF quality of life assessment. The WHOQOL Group. Psychol Med. 1998; 28:551-8.

26. World Health Organization. Programme on mental health. WHOQOL-BREF Introduction, administration, scoring and generic version of the assessment. Field Trial Version 1996.

27. The World Health Organization Quality of Life Assessment (WHOQOL): development and general psychometric properties. Soc Sci Med 1998;46:1569-85.

28. Garratt A, Schmidt L, Mackintosh A, Fitzpatrick R. Quality of life measurement: bibliographic study of patient assessed health outcome measures. BMJ. 2002; 324:1417.
29.30. Ware JE. SF-36 Health Survey: Manual \& interpretation guide. Boston, MA: The Health Institute. New England Medical Center. 1993

30. Huang IC, Wu AW, Frangakis C. Do the SF-36 and WHOQOL-BREF measure the same constructs? Evidence from the Taiwan population. Qual Life Res. 2006; 15:15-24.

31. Asadi-Lari M, Packham C, Gray D. Patients satisfaction and quality of life in coronary artery disease Health and Quality of Life Outcomes 2003; 1:57-68.

32. Rabin R, Charro F. EQ-5D: a measure of health status from the EuroQol Group. Ann Med 2001; 33:337-43.

33. Meenan RF, Gertman PM, Mason JH. Measuring health status in arthritis: The Arthritis WAImpact Measurement Scales. Arthritis and Rheumatism. 1980; 23:146-152.

34. Aaronson NK, Ahmendzai S, Bergman B, et al. The European Organization for Research and Treatment of Cancer QLQ-C30: A quality of life instrument for use in international clinical trials in oncology. Journal of the National Cancer Institute. 1993; 85:365-376.

35. Gauthier-Gagnon C, Grisé MC. Prosthetic profile of the amputee questionnaire: validity and reliability of the of the follow-up questionnaire. Arch Phys Med Rehabil. 1994; 75:1309-14.

36. Guyatt GH, Feeny DH, Patrick DL. Measuring health-related quality of life. Ann Intern Med. 1993; 118:622-9.

37. Guyatt GH, Thompson PJ, Berman LB, et al. How should we measure function in patients with chronic heart and lung disease? J Chronic Dis. 1985; 38:517-24. 


\title{
HEALTH-RELATED QUALITY OF LIFE MEASUREMENT AS THE STANDARD FOR THE HEALTH CARE EFFICIENCY
}

\author{
Boris Kovač \\ Faculty of Health Studies, University of Mostar, Bosnia \& Herzegovina
}

\begin{abstract}
Measurement of quality of life in medical science and health-related quality of life are accepted tools for assessing the impact of the disease and the different methods of treatment to the patient's physical or emotional condition in daily activities. Health-related quality of life is part of the general concept of quality of life that relates specifically to a person's health, and indicates the measurement of functioning, well-being and general health perception of patients in three domains: physical, mental and social. Instruments for measuring the health-related quality of life are based on the concept of health that is multi-dimensional, and the source of information is the patient himself. They may be classified as a generic or specific. Generic instruments assess the concept of health, which is a fundamental human value and relate to the health and well-being of every individual, regardless of age, disease or mode of treatment. Specific instruments are directed to a specific disease, condition or treatment. Today in modern clinical medicine, there are increasing demands for testing the effectiveness, safety and cost-effectiveness of new treatment strategy that, in addition to cost-benefit ratio, include the patient's sense of health as a measure of treatment success.

The aim of this paper is to present the fundamental methodology, methods and importance of health-related quality of life measurement in the process of evaluating the performance of health care.
\end{abstract}

Keywords: quality of life, health, disease, questionnaire.

Correspondence:

Boris Kovač

E-mail: boris.v.kovac@gmail.com 